\title{
Calmodulin-Dependent Kinase Kinase/Calmodulin Kinase I Activity Gates Extracellular-Regulated Kinase-Dependent Long-Term Potentiation
}

\author{
John M. Schmitt, ${ }^{\star}$ Eric S. Guire, ${ }^{\star}$ Takeo Saneyoshi, and Thomas R. Soderling \\ Vollum Institute, Oregon Health and Sciences University, Portland, Oregon 97239
}

\begin{abstract}
Intracellular $\mathrm{Ca}^{2+}$ and protein phosphorylation play pivotal roles in long-term potentiation (LTP), a cellular model of learning and memory. $\mathrm{Ca}^{2+}$ regulates multiple intracellular pathways, including the calmodulin-dependent kinases (CaMKs) and the ERKs (extracellular signal-regulated kinases), both of which are required for LTP. However, the mechanism by which $\mathrm{Ca}^{2+}$ activates ERK during LTP remains unknown. Here, we describe a requirement for the CaMK-kinase (CaMKK) pathway upstream of ERK in LTP induction. Both the pharmacological inhibitor of CaMKK, STO-609, and dominant-negative CaMKI (dnCaMKI), a downstream target of CaMKK, blocked neuronal NMDA receptor-dependent ERK activation. In contrast, an inhibitor of CaMKII and nuclear-localized dnCaMKIV had no effect on ERK activation. NMDA receptor-dependent LTP induction robustly activated CaMKI, the $\mathrm{Ca}^{2+}$-stimulated Ras activator Ras-GRF1 (Ras-guanyl-nucleotide releasing factor), and ERK. STO-609 blocked the activation of all three enzymes during LTP without affecting basal synaptic transmission, activation of CaMKII, or cAMP-dependent activation of ERK. LTP induction itself was suppressed $\sim 50 \%$ by ST0-609 in a manner identical to the ERK inhibitor U0126: either inhibitor occluded the effect of the other, suggesting they are part of the same signaling pathway in LTP induction. ST0-609 also suppressed regulatory phosphorylation of two downstream ERK targets during LTP, the general translation factors eIF4E (eukaryotic initiation factor 4) and its binding protein 4E-BP1 (eukaryotic initiation factor $4 \mathrm{E}$-binding protein 1). These data indicate an essential role for CaMKK and CaMKI to link NMDA receptor-mediated $\mathrm{Ca}^{2+}$ elevation with $^{2}$ ERK-dependent LTP.
\end{abstract}

Key words: calcium; CaM kinase; ERK; LTP; synaptic plasticity; eIF4E

\section{Introduction}

Protein phosphorylation is one of the most prevalent mechanisms for modulating neuronal functions, including long-term potentiation (LTP) (Kandel, 2001; Lisman et al., 2002), a cellular model of learning and memory (Malenka, 2003; Lynch, 2004). Two protein kinase families highly expressed in brain that have been implicated in molecular mechanisms regulating LTP are the $\mathrm{Ca}^{2+} /$ calmodulin-dependent kinases (CaMKs) and ERK1 and ERK2 (extracellular signal-regulated kinases) (Soderling, 2000; Sweatt, 2004). The CaMK family, which is activated in response to elevations of intracellular $\mathrm{Ca}^{2+}$, includes CaMKII (Soderling et al., 2001; Lisman et al., 2002; Colbran and Brown, 2004) and the CaMK-kinase (CaMKK) cascade consisting of CaMKK and its two major downstream targets CaMKI and CaMKIV (Soderling, 1999; Means, 2000). CaMKII regulates numerous neuronal

Received Oct. 1, 2004; revised Dec. 16, 2004; accepted Dec. 20, 2004.

This work was supported by National Institutes of Health (NIH) R01 Grants NS27037 (T.R.S.) and GM41292 (T.R.S.), an N. L. Tartar fellowship (E.S.G.), NIH Training Grant DK007680 (J.M.S.), and Human Frontier Science Program Fellowship LT00193 (T.S.). We thank members of the Soderling laboratory (Dr. Monika Davare, Dr. Victor Derkach, Dr. Gary Wayman, and Wilmon Grant) for helpful discussions and technical assistance, and Drs. Philip Stork and Soren Impey for critiquing this manuscript.

*J.M.S. and E.S.G. contributed equally to this work.

Correspondence should be addressed to Thomas R. Soderling, Oregon Health and Science University, Vollum Institute, 3181 Southwest Sam Jackson Park Road, Portland, 0R 97239. E-mail: soderlit@ohsu.edu.

D0I:10.1523/JNEUROSCI.4086-04.2005

Copyright $\odot 2005$ Society for Neuroscience $\quad$ 0270-6474/05/251281-10\$15.00/0 functions, including phosphorylation of the AMPA-type glutamate receptor (GluR), resulting in increased conductance during early-phase LTP (E-LTP) (Soderling and Derkach, 2000; Song and Huganir, 2002). CaMKIV is primarily restricted to the nucleus (Jensen et al., 1991; Lemrow et al., 2004), in which it stimulates gene transcription required for late-phase LTP (L-LTP) (Kang et al., 2001) through phosphorylation of transcription factors such as CREB (cAMP response element-binding protein) and CBP (CREB binding protein) (Enslen et al., 1994; Impey et al., 2002). Cytosolic CaMKI modulates cytoskeletal organization (Suizu et al., 2002) and axonal growth cone motility (Wayman et al., 2004), but a potential role for CaMKI in LTP has not been examined previously.

The ERK family of MAP (mitogen-activated protein) kinases are activated by growth factors, neurotransmitters, and hormones, as well as by $\mathrm{Ca}^{2+}$-permeable NMDA receptor (NMDA-R) and voltage-gated channels in neurons (Pearson et al., 2001; Thomas and Huganir, 2004). The NMDA-R gates many forms of synaptic plasticity, including hippocampal CA1 LTP (Malenka and Nicoll, 1999). Activation of ERK during neuronal depolarization or NMDA-R stimulation requires elevations of intracellular $\mathrm{Ca}^{2+}$, and it appears to be mediated through the classical Ras/Raf/MEK (MAP kinase kinase)/ERK cascade (Wu et al., 2001a,b; Agell et al., 2002). Recent studies suggest that RasGRF1 (Ras-guanyl-nucleotide releasing factor) may couple the 
NMDA-R $\mathrm{Ca}^{2+}$ elevation to Ras and ERK activation in neurons (Krapivinsky et al., 2003; Tian et al., 2004).

Induction of LTP activates ERK, and inhibitors of the ERK pathway (e.g., SL327 and U0126) partially suppress LTP induction (Sweatt, 2004; Thomas and Huganir, 2004). A role for ERK in the regulation of gene transcription during L-LTP is well established (Treisman, 1996; Kelleher et al., 2004), and a role of ERK in mRNA translation has been reported recently (Kelleher et al., 2004). Expression of dominant-negative (dn) MEK1 in region CA1 of the hippocampus suppresses hippocampal-dependent memory tasks in mice, ERK activation, and anisomysin-sensitive LTP in hippocampal slices, as well as mRNA translation in cultured hippocampal neurons.

Because of the key role of ERKs in modulating $\mathrm{Ca}^{2+}$ dependent neuronal plasticity, it was important to determine whether the recently identified crosstalk between CaMKK/ CaMKI and ERK (Schmitt et al., 2004) regulate LTP. The results of this study provide strong evidence that CaMKK and CaMKI are essential for the full expression of LTP and ERK-dependent translational activation.

\section{Materials and Methods}

Antibodies and plasmids. The following reagents were purchased from the indicated sources: U0126 and forskolin from Calbiochem (Riverside, CA); STO-609, NMDA, and APV from Tocris Cookson (Ellisville, MO); and anisomycin from Alexis Biochemicals (San Diego, CA). Phosphospecific antibodies were purchased from the following sources: ERK1/2 $\left(\mathrm{Thr}^{202}, \mathrm{Tyr}^{204}\right.$ ), Ras-GRF1 (Ser ${ }^{916}$ ), eIF4E (eukaryotic initiation factor 4) $\left(\operatorname{Ser}^{209}\right), 4 \mathrm{E}-\mathrm{BP} 1$ (eukaryotic initiation factor $4 \mathrm{E}$-binding protein 1 ) $\left(\mathrm{Ser}^{65}\right)$, and AKT $\left(\mathrm{Thr}^{308}\right.$ ) from Cell Signaling Technology (Beverly, MA); CaMKII (Thr ${ }^{286}$ ) and GluR1 subunit of the AMPA-R $\left(\mathrm{Ser}^{831}\right)$ from Affinity BioReagents (Golden, CO); and CaMKI $\left(\mathrm{Thr}^{177}\right.$ ) from Dr. Naohito Nozaki (Kanagawa Dental College, Yokosuka, Kanagawa, Japan) (Schmitt et al., 2004; Wayman et al., 2004). Other antibodies were purchased from the indicated sources: AKT, Ras-GRF1, eIF4E, and 4EBP1 from Cell Signaling Technology; ERK2 (D-2) from Santa Cruz Biotechnology (Santa Cruz, CA); CaMKII from Transduction Laboratories (Lexington, KY); CaMKI from Dr. Kohji Fukunaga (Tohoku University, Sendai, Japan); and Flag (M2) from Sigma (St. Louis, MO). The dnCaMKK (K71A, T108A, S458A), dnCaMKI (K49E, T177A, 7IHQS286EDDD, F307A), dnCaMKIV nuclear (T196A, K71E, HMDT305DEDD), and CaMKIIN plasmids have been described previously (Schmitt et al., 2004; Wayman et al., 2004). The Flag-ERK2 plasmid was provided by Dr. Philip Stork (Vollum Institute, Portland, OR). The RasGRF1 construct was purchased from Open Biosystems (Huntsville, AL).

Primary hippocampal neuronal culture and treatments. Neurons were isolated from the hippocampus of postnatal day 1-2 Sprague Dawley rats. Neurons were grown 5-6 d in vitro (DIV) (unless otherwise indicated) and placed in serum-free isotonic media consisting of $130 \mathrm{~mm}$ $\mathrm{NaCl}, 2.5 \mathrm{~mm} \mathrm{KCl}, 1 \mathrm{~mm} \mathrm{MgCl}_{2}, 2 \mathrm{~mm} \mathrm{CaCl}_{2}, 25 \mathrm{~mm} \mathrm{HEPES}-\mathrm{HCl}$, and 30 $\mathrm{mM}$ D-glucose for $60 \mathrm{~min}$ at $37^{\circ} \mathrm{C}$ with pharmacological inhibitors $(5 \mu \mathrm{M}$ STO-609 for $60 \mathrm{~min}$; $10 \mu \mathrm{M}$ U0126 for $20 \mathrm{~min}$ ), as indicated before stimulation. Cells were stimulated with serum- and magnesium-free isotonic media containing NMDA $(25 \mu \mathrm{M})$ and glycine $(1 \mu \mathrm{M})$ for the indicated times.

For transfections, 5-d-old hippocampal neurons were cotransfected with Flag-ERK2, along with the control vector pcDNA3, or the indicated plasmids using Lipofectamine 2000 (Invitrogen, San Diego, CA) according to the guidelines of the manufacturer. After transfection, neurons were allowed to recover in complete media for $24 \mathrm{~h}$, placed in serum-free isotonic media for $60 \mathrm{~min}$ (see above), treated as indicated, and lysed in ice-cold lysis buffer as detailed below. Lysates were then examined for the presence of Flag-ERK2 or myc-Ras-GRF1 (Open Biosystems) expression by Western blotting, and Flag-ERK2 or myc-Ras-GRF1 were immunoprecipitated and examined by Western blotting for activation.

Western blotting and immunoprecipitation of primary hippocampal neurons. For direct Western blotting after primary hippocampal neuron stimulations, media was aspirated, and boiling Laemmeli's buffer (supplemented with $200 \mathrm{~mm}$ EDTA, 20 mm EGTA, $200 \mathrm{~mm} \mathrm{NaF}, 20 \mathrm{~mm}$ $\beta$-glycerophosphate, $1 \mathrm{~mm}$ PMSF, and $5 \mu \mathrm{M}$ microcystin) was added to each plate of cells. Plates were scraped, and cellular lysates were placed in microcentrifuge tubes, rapidly vortexed, boiled for $5 \mathrm{~min}$, and centrifuged at $8000 \mathrm{rpm}$ for $3 \mathrm{~min}$ to pellet insoluble materials. Equivalent amounts of protein were resolved by SDS-PAGE, blotted onto polyvinylidene difluoride membranes (PVDF), and examined by Western blotting with the indicated antibodies.

For immunoprecipitations after primary hippocampal neuron stimulations, media was aspirated, and ice-cold lysis buffer (10\% glycerol, 1\% NP-40, 50 mм Tris-HCl, pH 7.4, $200 \mathrm{~mm} \mathrm{NaCl}$, and $2 \mathrm{~mm} \mathrm{MgCl}_{2}$ ) containing freshly added inhibitors ( $1 \mathrm{~mm}$ PMSF, $2 \mu \mathrm{g} / \mathrm{ml}$ aprotinin, $1 \mu \mathrm{g} / \mathrm{ml}$ leupeptin, $10 \mu \mathrm{g} / \mathrm{ml}$ trypsin inhibitor, and $1 \mathrm{~mm}$ sodium orthovanadate) was added to each plate of cells on ice. Plates were scraped, and cellular proteins were placed in ice-cold microcentrifuge tubes. Briefly, cell lysates were spun at $8000 \mathrm{rpm}$ for $5 \mathrm{~min}$ at $4^{\circ} \mathrm{C}$ to pellet the cytoskeleton and nuclei. Immunoprecipitations were performed at $4^{\circ} \mathrm{C}$ for $4 \mathrm{~h}$ in ice-cold lysis buffer (Schmitt et al., 2004). Precipitated proteins were washed two times with lysis buffer, placed in Laemmeli's buffer, resolved by SDS-PAGE, and Western blotted for phosphorylated Flag-ERK2 (pFlag-ERK2, pFlag-ERK2, or myc-Ras-GRF1). Western blotting for total Flag-ERK2 with anti-Flag antibody was performed on lysates to serve as a loading and transfection control. For quantitation of Western blots, autoradiographs were scanned and densitized using Kodak ID 3.0.2 system software (Eastman Kodak, New Haven, CT). For each phosphoprotein of interest, separate Western blots were run for that phosphoprotein (e.g., pCaMKI) and for the total protein (CaMKI). For each Western blot, band densities were first normalized to untreated controls, then phospho-protein was normalized to total protein, and the value was presented as fold increase in phosphorylation relative to the control.

Mouse hippocampal slice production and treatments. Adult male C57BL/6 mice (8-12 weeks old; Charles River Laboratories, Wilmington, MA) were anesthetized with pentobarbital $(60 \mathrm{mg} / \mathrm{kg}$, i.p. $)$ and decapitated using procedures reviewed and approved by Institutional Animal Care and Use Committee at the Oregon Health and Sciences University Department of Comparative Medicine. Brains were removed within 1 min of decapitation and immediately submerged in ice-cold, sucrose-modified artificial CSF (ACSF) for hippocampal dissection and slicing (in mM): 110 sucrose, $60 \mathrm{NaCl}, 2.5 \mathrm{KCl}, 28 \mathrm{NaHCO}_{3}, 1.25$ $\mathrm{NaH}_{3} \mathrm{PO}_{4}, 0.5 \mathrm{CaCl}_{2}, 7 \mathrm{MgCl}_{2}, 5$ glucose, and 0.6 sodium ascorbate, $\mathrm{pH}$ 7.4 , at $4^{\circ} \mathrm{C}$ (presaturated by bubbling with $95 \% \mathrm{O}_{2} / 5 \% \mathrm{CO}_{2}$ at $21-22^{\circ} \mathrm{C}$ ). Hippocampal slices (400 $\mu \mathrm{m}$, transverse) were prepared using a vibratome and an agar backing (2\%), and each slice was transferred to warm ACSF [in mm: $125 \mathrm{NaCl}, 2.5 \mathrm{KCl}, 22.6 \mathrm{NaHCO}_{3}, 1.25 \mathrm{NaH}_{3} \mathrm{PO}_{4}, 2$ $\mathrm{CaCl}_{2}, 1 \mathrm{MgCl}_{2}$, and 11.1 glucose (continuously gas saturated with $95 \%$ $\mathrm{O}_{2} / 5 \% \mathrm{CO}_{2}, \mathrm{pH} 7.4$ at $\left.\left.32^{\circ} \mathrm{C}\right)\right]$ for recovery $\left(30 \mathrm{~min}, 37^{\circ} \mathrm{C}\right)$. Slices from the dorsal and ventral thirds of the hippocampus were discarded. After recovery, the chamber was equilibrated at $21-22^{\circ} \mathrm{C}$, and slices were held for 2-8 $\mathrm{h}$ before recording or $1 \mathrm{~h}$ before beginning NMDA and forskolin treatments. For NMDA and forskolin treatments, slices were then placed at $30^{\circ} \mathrm{C}$ for 1 additional hour, in the presence or absence of pharmacological inhibitors (5 $\mu \mathrm{M} \mathrm{ST0}-609$ for $60 \mathrm{~min}, 10 \mu \mathrm{M}$ U0126 for $20 \mathrm{~min}$, and $50 \mu \mathrm{M}$ APV for $20 \mathrm{~min}$ ), before chemical stimulations. Hippocampal slices were then stimulated with NMDA plus glycine ( 25 and $1 \mu \mathrm{M}$, respectively) or forskolin $(50 \mu \mathrm{M})$ for the indicated times in ACSF, in the presence or absence of STO-609 or U0126. After chemical stimulation, and at various time points after the electrical induction of LTP, slices were frozen on a filter paper-covered liquid nitrogen-cooled aluminum block and placed in microcentrifuge tubes in pairs. Slices were kept submerged at all times until frozen. For LTP experiments, area CA1 was isolated by microdissection after freezing. Ice-cold lysis buffer (10\% glycerol, 1\% NP-40, $50 \mathrm{~mm}$ Tris- $\mathrm{HCl}, \mathrm{pH} 7.4,200 \mathrm{~mm} \mathrm{NaCl}$, and $2 \mathrm{~mm}$ $\mathrm{MgCl}_{2}$ ) plus freshly added inhibitors ( $1 \mathrm{~mm}$ PMSF, $2 \mu \mathrm{g} / \mathrm{ml}$ aprotinin, 5 $\mu \mathrm{M}$ microcystin, $1 \mu \mathrm{g} / \mathrm{ml}$ leupeptin, $10 \mu \mathrm{g} / \mathrm{ml}$ trypsin inhibitor, and $1 \mathrm{mM}$ sodium orthovanadate) was added to each tube containing frozen slices, which were rapidly homogenized as they thawed in lysis buffer. Laemmeli's buffer $(6 \times)$ was then added, and tubes were rapidly vortexed and boiled for $5 \mathrm{~min}$. Equivalent volumes of lysate were resolved by SDS- 
PAGE, blotted onto PVDF membranes, and examined by Western blotting with the indicated antibodies.

Electrophysiology. For electrophysiological recordings, submerged hippocampal slices were suspended in pairs on a nylon mesh in a small $(350-400 \mu \mathrm{l})$ recording chamber and perfused with ACSF at a rate of $2.5-3 \mathrm{ml} / \mathrm{min}$. The temperature in the recording chamber was raised to $30-32^{\circ} \mathrm{C}$ over the course of a few minutes and held for the duration of the experiment. Synaptic responses were evoked by Schaffer collateral stimulation using a bipolar tungsten electrode (tip spacing, $140 \mu \mathrm{m}$; Frederick Haer Company, Bowdoinham, ME) and a $100 \mu$ s square wave test pulse (typically $30-40 \mu \mathrm{A}$ ) delivered at $60 \mathrm{~s}$ intervals. The stimulation intensity was adjusted to produce a basal response of 1.2-1.4 $\mathrm{mV}$ [typically $25 \%$ of the maximum field EPSP (fEPSP) amplitude]. Recordings were made using ACSF-filled glass micropipettes (2-4 M $\Omega$ ) placed in the stratum radiatum area of CA1 (see Fig. $2 C$ ) and connected via head stages to an A-M Systems (Carlsborg, WA) model 1800 amplifier. Signals were digitized at $100 \mathrm{kHz}$ using the Axon Instruments (Union City, CA) Digidata 1200 series interface running Clampex 8.0, and the initial slope (linear portion of the first millisecond) of the fEPSPs were analyzed with Clampfit 8.0 software. Drug treatments began $30 \mathrm{~min}$ (STO-609, U0126, and anisomycin) or $20 \mathrm{~min}$ (APV) before and ended (with the exception of anisomycin) $5 \mathrm{~min}$ after the induction of LTP using theta bursts. Anisomycin treatments persisted for the duration of the recordings. E-LTP was induced using an acute theta-burst protocol: four pulses per burst $(100 \mathrm{~Hz})$, five bursts per train $(5 \mathrm{~Hz})$, three trains (beginning $20 \mathrm{~s}$ apart). L-LTP was induced using a recurrent theta-burst protocol: four epochs of the acute theta-burst protocol delivered $5 \mathrm{~min}$ apart. With the exception of the first data point after LTP induction (posttetanic potentiation), 3 min fEPSP averages are shown. The first data point after LTP induction was taken $20 \mathrm{~s}$ after the final train of theta bursts. All treatment groups were balanced such that the average time of the slices in the recording chamber was equal and the average age of animals was equal.

Statistics. To determine whether significant differences existed among treatments, an ANOVA was performed on the data with significance set at 0.05 . To compare whether significant differences existed between two treatments, a Student's $t$ test was performed on the data with significance set at 0.05 . Significance levels ( $p$ value) are indicated in the figures: ${ }^{*} p \leq$ $0.05,{ }^{* *} p \leq 0.01$, and ${ }^{* *} p \leq 0.001$.

\section{Results}

\section{NMDA activation of ERK requires CaMKK and CaMKI}

To investigate the potential role of CaMKs in NMDA-dependent ERK activation in hippocampal neurons, we used the membranepermeable CaMKK inhibitor STO-609 (Tokumitsu et al., 2002) or expression of dnCaMKs or the CaMKII inhibitor protein CaMKIIN (Chang et al., 1998). STO-609 appears to be highly specific for CaMKK: (1) it has an in vitro $\mathrm{IC}_{50}$ of $0.13-0.38 \mu \mathrm{M}$ for CaMKK and $32 \mu \mathrm{M}$ for CaMKII with little or no inhibition of CaMKI, CaMKIV, PKA (protein kinase A), PKC, ERK, or myosin light chain kinase (Tokumitsu et al., 2002); and (2) in cultured hippocampal neurons (Wayman et al., 2004) and NG108 cells (Schmitt et al., 2004) subjected to depolarization, STO-609 inhibits CaMKK activation, as assessed by its ability to block phosphorylation of the activation loop $\mathrm{Thr}^{177}$ in CaMKI, with no effect on CaMKII activation (i.e., autophosphorylation of $\mathrm{Thr}^{286}$ ). Furthermore, we used dnCaMKs as an independent confirmation of the involvement of this pathway. CaMKIIN is an endogenous CaMKII inhibitor protein ( $\mathrm{IC}_{50}$ of $50-100 \mathrm{nM}$ ) that exhibits no in vitro inhibition of CaMKI, CaMKIV, CaMKK, PKA, PKC (Chang et al., 1998), or ERK (S. Nygaard and T. R. Soderling, unpublished result). When transfected into cultured hippocampal neurons, CaMKIIN potently blocks CaMKII activation (Wayman et al., 2004) but not ERK activation (Schmitt et al., 2004) during depolarization.

Stimulation of cultured hippocampal neurons with NMDA activated endogenous ERK within $5 \mathrm{~min}$, an effect that was com- pletely blocked by either the MEK inhibitor U0126 or by STO609 (Fig. 1 A), indicating involvement of the CaMKK cascade. To confirm the specificity of STO-609, we used a mutant (L233F) of CaMKK (Tokumitsu et al., 2002) that is insensitive to inhibition by this compound. Transfection of neurons with $\mathrm{CaMKK}_{\mathrm{L} 233 \mathrm{~F}}$ completely rescued inhibition by STO-609 (Fig. $1 \mathrm{~A}$ ), establishing that STO-609 was exerting its effect through CaMKK. To further characterize which member of the CaMKK cascade mediated ERK activation, hippocampal neurons were cotransfected with Flag-ERK2 plus various dominant-negative CaMK constructs. ERK activation was completely inhibited by dnCaMKK, as well as by dnCaMKI (Fig. $1 B$ ). Endogenous CaMKIV is predominantly nuclear restricted (Lemrow et al., 2004), and nuclear-localized (nuc) dnCaMKIVnuc did not block ERK activation (Fig. 1B), although we have shown previously that it suppressed NMDAstimulated CREB-dependent transcription in neurons (Wayman et al., 2004). To examine the role of CaMKII, we expressed the specific CaMKII inhibitor protein CaMKIIN (Chang et al., 1998) that completely blocked neuronal CaMKII activation in response to depolarization (Wayman et al., 2004). CaMKIIN had no effect on NMDA-dependent ERK activation (Fig. 1B). These results demonstrate in cultured hippocampal neurons that NMDAdependent activation of ERK was mediated by the CaMKK and CaMKI pathway but not by CaMKII or nuclear CaMKIV.

Next, we examined the role of CaMKK in ERK activation using acute mouse hippocampal slices. The rapid activation of ERK in response to NMDA treatment was blocked by the NMDA receptor antagonist $\mathrm{APV}$, the MEK inhibitor U0126, and the CaMKK inhibitor STO-609 (Fig. 1C,D). CaMKK and CaMKI were also rapidly activated by NMDA as assessed by phosphorylation of the activation loop $\mathrm{Thr}^{177}$ in CaMKI (a target of CaMKK), and, as expected, these were also inhibited by STO-609 but not U0126 (Fig. 1E). In agreement with previous studies (Fukunaga et al., 1992), CaMKII was also activated (i.e., autophosphorylation of $\mathrm{Thr}^{286}$ ) by NMDA stimulation, and one of its substrates, Ser ${ }^{831}$, in the GluR1 subunit of the AMPA-R was phosphorylated (Barria et al., 1997), but neither of these reactions was inhibited by STO-609 or U0126 (Fig. $1 F$ ). This result confirms our previous observation that STO-609 does not block CaMKII activation in hippocampal neurons (Wayman et al., 2004) or NG108 cells (Schmitt et al., 2004). The specificity of STO-609 for CaMKK was further demonstrated by the fact that activation of ERK in response to forskolin treatment, which was NMDA-receptor independent (Fig. 1C), was not blocked by STO-609 but was suppressed by U0126 (Fig. 1G).

We have shown previously a requirement for the small G-protein Ras in the CaMKK/CaMKI activation of ERK during depolarization (Schmitt et al., 2004). Ras is required for NMDA receptor-dependent activation of ERK in neurons (Zhu et al., 2002), and the dnRas RasN17 blocked ERK activation in response to NMDA treatment of cultured hippocampal neurons in our experiments (data not shown). Furthermore, recent studies demonstrate the involvement of the $\mathrm{Ca}^{2+}$-dependent Ras activator Ras-GRF1 in ERK activation (Krapivinsky et al., 2003; Tian et al., 2004). Phosphorylation of Ras-GRF1 at Ser ${ }^{916}$ appears to play a pivotal role in its physiological functions and serves as a readout for activation (Mattingly, 1999; Yang et al., 2003). Endogenous Ras-GRF1 was rapidly phosphorylated on $\mathrm{Ser}^{916}$ in response to NMDA treatment, an effect that was blocked by STO-609 but not U0126 (Fig. $1 \mathrm{H}$ ). To confirm the roles for CaMKK and CaMKI in Ras-GRF1 phosphorylation, cultured hippocampal neurons were cotransfected with myc-Ras-GRF1 plus dnCaMKI or CaMKIIN. Ras-GRF1 phosphorylation was completely suppressed by 
dnCaMKI but not by the CaMKII inhibitor (Fig. 1I). Together, the data of Figure 1 support the specificity of STO-609 for CaMKK and suggest that the requirement for CaMKK/CaMKI in NMDAdependent ERK activation in hippocampal neurons is upstream of Ras-GRF1.

\section{Induction of LTP requires the CaMKK pathway}

The CaMKK cascade can mediate NMDA receptor-dependent ERK activation (Fig. 1) and ERK plays an important role in LTP induction (Sweatt, 2004; Thomas and Huganir, 2004), so we investigated the role of CaMKK in LTP induction. Mouse hippocampal slices treated with STO-609 exhibited a normal input-output relationship over a wide range of stimulus intensities (Fig. 2A), as well as normal paired-pulse facilitation (Fig. 2B), indicating that acute blockade of the CaMKK pathway does not effect basal synaptic transmission. Additionally, we integrated the area above the curve of the fEPSPs during stimulation with thetaburst trains (E-LTP protocol, see Materials and Methods) and found no significant difference among the dendritic field responses of STO-609- or U0126-treated and untreated slices during E-LTP induction (Fig. 2C). This finding held true for the first (naive) theta bust, each individual train, the plasticity within each train (area of burst 5 /burst 1 ), as well as the sum of all trains. These results indicate that STO-609 does not impair normal synaptic transmission nor the dendritic field response to high-frequency theta-burst trains, important prerequisites for our study of the role of CaMKK in LTP.

To determine whether CaMKK and its downstream targets are involved in the induction of early-phase LTP (E-LTP), we treated acute hippocampal slices with 5 $\mu \mathrm{M}$ STO-609. Analysis of the initial slope of fEPSPs taken from area CA1 (Fig. 2C) before and after theta-burst stimulation (see Materials and Methods) revealed a significant ( $~ 50 \%$ ) STO-609 sensitivity of E-LTP out to $60 \mathrm{~min}$ (Fig. 2D). Our acute theta-burst protocol produced activation of CaMKI and ERK within 5 min, effects that were completely blocked by the NMDA receptor antagonist APV, as was the induction of E-LTP (Fig. 2E).

The role of CaMKK in L-LTP lasting $3 \mathrm{~h}$ was examined using a recurrent thetaburst protocol spaced over $15 \mathrm{~min}$ (see Materials and Methods). Again, STO-609 treatment gave 50\% suppression over the first hour and completely obviated LTP at $3 \mathrm{~h}$ (Fig. $2 \mathrm{~F}$ ), demonstrating that the requirement for CaMKK in the first hour of LTP was not overcome by a more robust induction protocol. Although CaMKIV is also activated by CaMKK, it does not
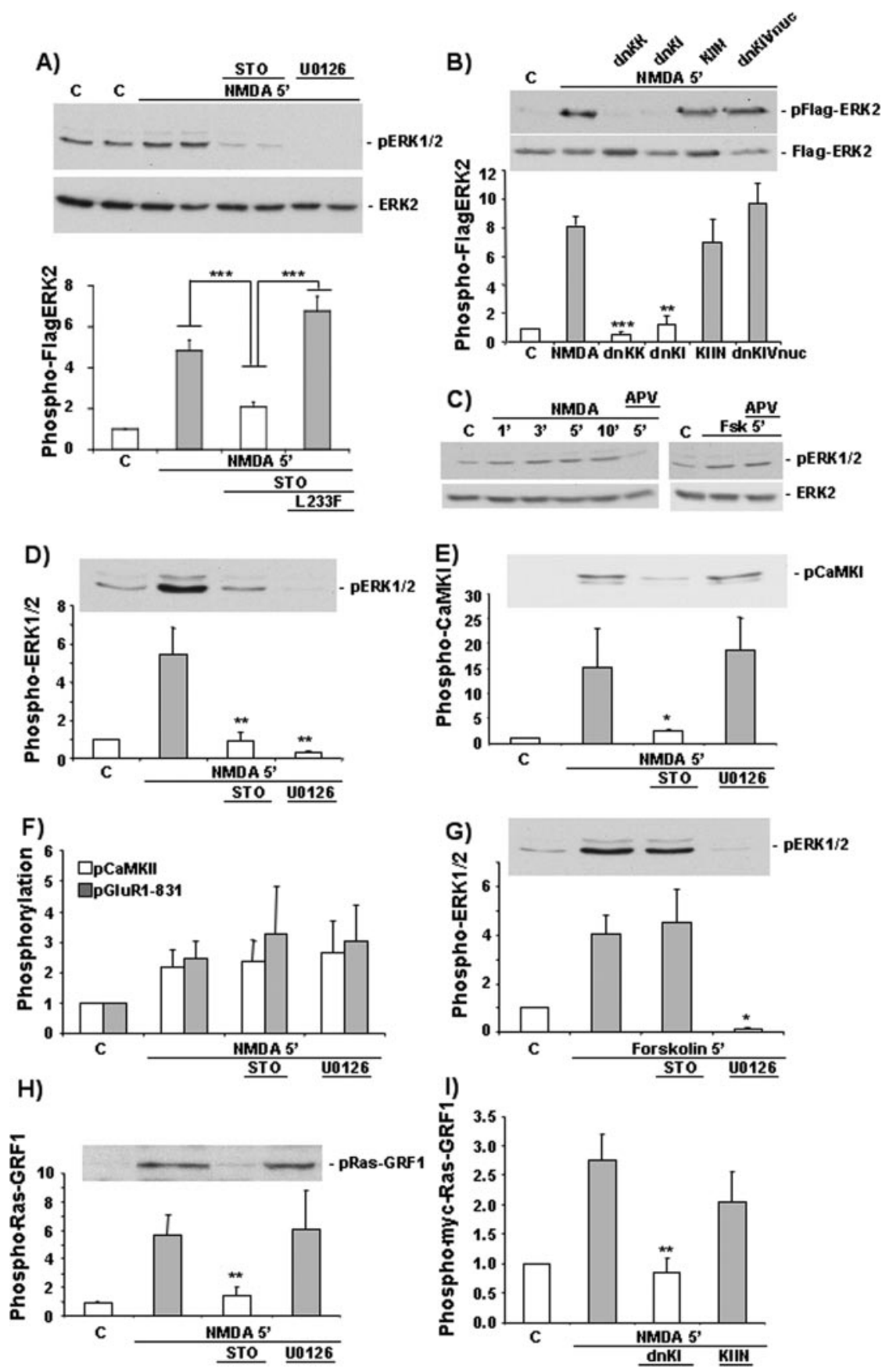

Figure 1. NMDA activation of ERK and Ras-GRF1 in hippocampus requires CaMKK and CaMKI. Primary cultures of rat hippocampal neurons ( $A, B, I, 6$ DIV) or acute mouse hippocampal slices ( $C-H, 8-12$ weeks old) were preincubated with the indicated pharmacological reagents [STO-609 (STO), $5 \mu \mathrm{m}, 60 \mathrm{~min}$; U0126, $10 \mu \mathrm{m}, 20 \mathrm{~min} ; \mathrm{APV}, 50 \mu \mathrm{m}, 20 \mathrm{~min}$ ] before stimulation by NMDA/glycine (25 and $1 \mu \mathrm{m}$, respectively) or forskolin (Fsk; $50 \mu \mathrm{m}$ ) for $5 \mathrm{~min} . A, B, I$, Cultured rat hippocampal neurons (5 DIV) were cotransfected with Flag-ERK2 and either CaMKK ${ }_{\text {L233F }}$ (L233F, a ST0-609-insensitive mutant; $A$, bottom graph) or myc-RasGRF1 plus control vector pcDNA3 or the indicated dnCaMKs or CaMKIIN as indicated. Cells were stimulated with NMDA, and Flag-ERK2 or myc-Ras-GRF1 phosphorylation was determined (see Materials and Methods). In all experiments, the activation states of the indicated proteins were determined by Western blots using phospho-specific antibodies (see Materials and Methods). The ratio of the phospho-protein to total amount of that same protein was set equal to 1 for the control, and relative values for treatments are shown as fold stimulation over basal. Means $\pm S D ; n=6(A), n=3(B), n=5(D-H)$, or $n=6(I) .{ }^{*} p \leq 0.05$; ${ }^{* *} p \leq 0.01 ;{ }^{* *} p \leq 0.001$. C, Control.

participate in E-LTP induced with either high-frequency stimulation (HFS) or recurrent theta bursts in mouse hippocampal region CA1 but is thought to contribute to CREB/CBP-dependent transcription during L-LTP (Ho et al., 2000; Kang et al., 2001). Based on these observations, we conclude that CaMKI mediated the down- 
A)

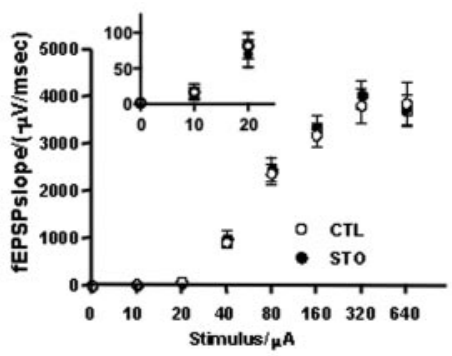

C)

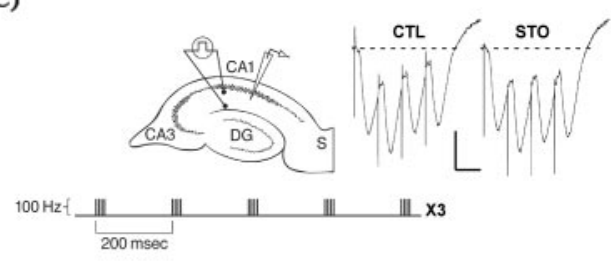

B)
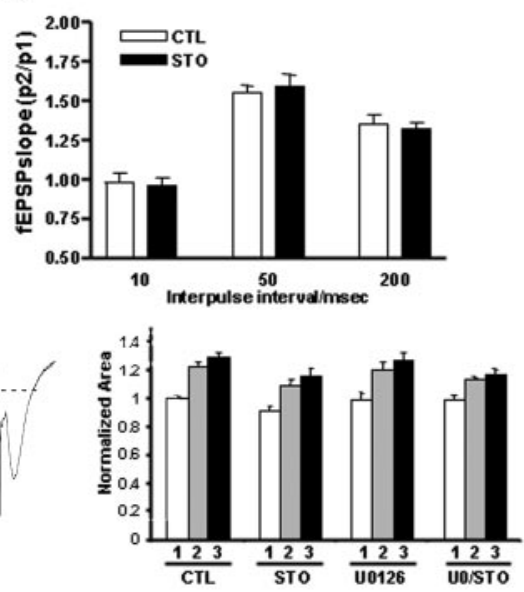

D)

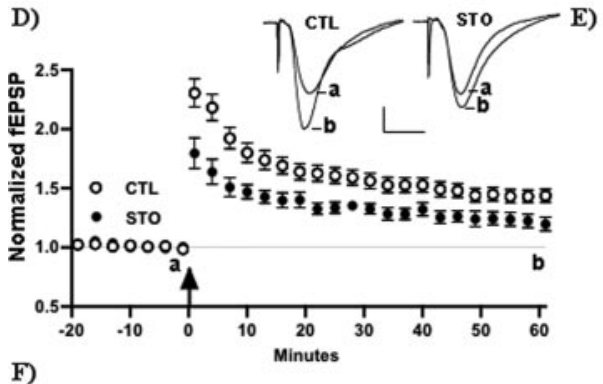

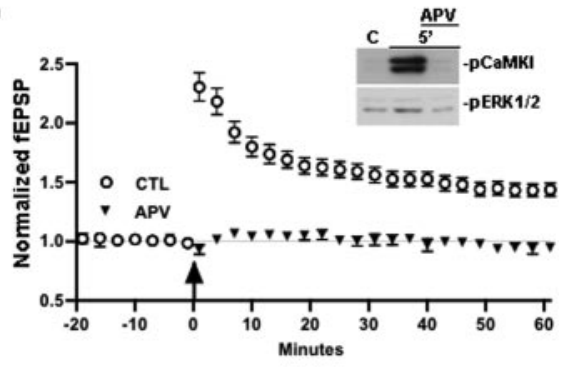

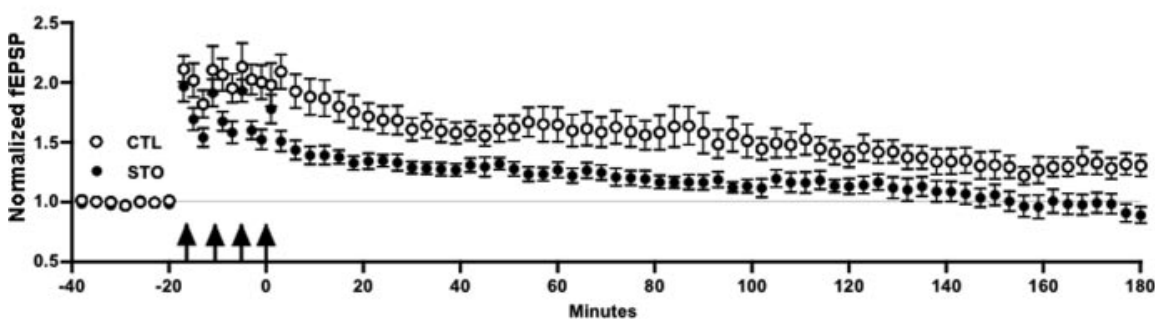

Figure 2. Inhibition of CaMKK markedly attenuates NMDA receptor-dependent LTP. A, ST0-609 does not affect basal synaptic transmission. Input- output relationship for Schaffer collateral stimulation and fEPSP initial slopes recorded from area CA1 of mouse hippocampal slices preincubated without or with $5 \mu \mathrm{m}$ STO-609 (STO) for $30 \mathrm{~min}$. Inset, $0-20 \mu \mathrm{A} ; n=8$. B, Paired-pulse facilitation is normal during ST0-609 treatment. Paired-pulse facilitation at 10, 50, and $200 \mathrm{~ms}$ interpulse intervals. Values presented are ratios of fEPSP initial slopes (pulse 2/pulse 1). $n=8$. C, Left, Schematic drawing of electrode placements during recording and E-LTP induction paradigm (see Materials and Methods). DG, Dentate gyrus; $S$, stratum radiatum. Middle, Representative first burst responses from mock-treated (control) and treated (STO) slices. Calibration: $0.5 \mathrm{mV}, 10 \mathrm{~ms}$. Right, Integrated dendritic theta-burst responses of control slices and treated slices: $n=24$, control; $n=11$, STO-609; $n=10$, U0126; $n=10$, U0126 plus ST0-609 U0/STO. The theta-burst responses were calculated by integrating the fEPSP response during stimulation of naive slices with our E-LTP-generating protocol. D, E, Inhibition of CaMKK partially inhibits NMDA receptor-dependent E-LTP. After $20 \mathrm{~min}$ of stable baseline recording ( 1 test pulse per minute $\mathrm{min}$ ), slices were treated for 30 min without or with $5 \mu \mathrm{M}$ STO-609 for $30 \mathrm{~min}(D)$ or with $50 \mu \mathrm{m} \mathrm{APV} \mathrm{for} 20 \mathrm{~min}(E)$ before and $5 \mathrm{~min}$ after theta-burst stimulation [ 4 pulses per burst $(100 \mathrm{~Hz}), 5$ bursts per train ( $5 \mathrm{~Hz}$ ), 3 trains (20 s apart)]. ST0-609 had no significant effect on baseline fEPSP amplitude or initial slope kinetics. Control slices (LTP, $144 \pm 5.4 \% ; n=24$ ) exhibited approximately twofold greater LTP than STO-treated slices (LTP, $120 \pm 5.9 \% ; n=11)$ at $60 \mathrm{~min}$, whereas APV treatment $(n=8)$ completely blocked LTP. D, Inset, Average of 10 responses, $1-10$ min before $(a)$ and 50 - 60 min after (b) LTP induction. E, Inset, Western blots from microdissected region CA1 showing pCaMKI and pERK 5 min after mock stimulation (control) or theta-burst stimulation without or with APV treatment. F, Inhibition of CaMKK blocks L-LTP. Slices were treated without or with ST0-609 as in D before stimulation with recurrent theta-burst patterned activity [4 pulses per burst ( $100 \mathrm{~Hz}), 5$ bursts per train $(5 \mathrm{~Hz}), 6$ trains ( $20 \mathrm{~s}$ apart), 4 epochs ( 5 min apart)] to generate late-phase LTP. Control, $n=6 ;$ ST0-609, $n=6$. CTL, Control.

stream effects of CaMKK during E-LTP, whereas CaMKIV may contribute significantly to L-LTP.

\section{CaMKK mediates ERK activation in E-LTP}

Induction of E-LTP in hippocampal slices activates ERK, and this activation is required for full expression of LTP (Selcher et al.,

2003). In light of our findings that CaMKI functions upstream of ERK activation, we examined whether the effects of STO-609 on LTP occurred upstream of ERK. Induction of LTP with our acute theta-burst protocol (see Materials and Methods) (Fig. 2D,E) resulted in threefold to fourfold activation of CaMKI and ERK within $5 \mathrm{~min}$ that was sustained for at least $60 \mathrm{~min}$ (Fig. $3 A, B$ ). Both CaMKI and ERK activation were suppressed by STO-609 at all time points examined. Another cytoplasmic target for CaMKK is the protein kinase AKT, which is slowly phosphorylated during depolarization of NG108 cells (Yano et al., 1998; Schmitt et al., 2004). A dnAKT (Yano et al., 1998) did not block ERK activation by NMDA treatment of cultured hippocampal neurons (data not shown) or during depolarization of NG108 cells (Schmitt et al., 2004). Induction of LTP in hippocampal slices produced a slow phosphorylation of AKT that was blocked by STO-609 (Fig. 3B). ERK was maximally activated within 5 min after LTP induction, whereas robust AKT activation was not observed until after 15 min (Fig. 3B). Therefore, we propose that CaMKK was not acting through AKT to activate ERK or to mediate LTP induction. However, endogenous Ras-GRF1 was significantly phosphorylated within $5 \mathrm{~min}$, and this was obviated by STO-609 treatment (Fig. 3C). LTP induction also resulted in rapid activation of CaMKII and phosphorylation of its substrate Ser $^{831}$ in the GluR1 subunit of the AMPA-R (Barria et al., 1997), but these effects were not suppressed by STO-609 (Fig. 3D). This confirms that STO-609 does not suppress other $\mathrm{Ca}^{2+}$-dependent pathways, such as CaMKII. These data support our conclusion that ERK activation during LTP is mediated by CaMKK acting through CaMKI.

\section{CaMKK and ERK mediate E-LTP by the} same pathway

As reported previously (Selcher et al., 2003), the MEK inhibitor U0126 produced a partial suppression of E-LTP elicited with theta bursts (Fig. 4A). The same drug application and acute theta-burst protocol was used here as in Figure 2, D and $E$. The inhibition of E-LTP by U0126 (Fig. 4A) was strikingly similar to that produced by STO-609 (Fig. 2D), consistent with the data in Figure 3 demonstrating that ERK activation during LTP is mediated by CaMKK. If this model is correct and the role of CaMKK in LTP induction is upstream of ERK, then the effect of U0126 should be occluded by STO-609 and visa versa. As shown in Figure $4 B$, combined bath treatment with U0126 plus STO-609 was no more effective at blocking E-LTP than treatment 
with STO-609 alone. In these experiments, U0126 completely blocked ERK activation at both 5 and $60 \mathrm{~min}$ (Fig. 4C). The specificity of U0126 was confirmed in that it did not inhibit activation of CaMKI, AKT, CaMKII, or Ras-GRF1 (Fig. 4D). These data demonstrate that the role of CaMKK in E-LTP is mediated by an ERKdependent mechanism.

\section{Role of CaMKK in translational activation during LTP}

A recent study (Kelleher et al., 2004) shows that protein synthesis-dependent L-LTP induced by four trains of HFS is partially suppressed in mice expressing a dominant-negative MEK1 (the upstream activator of ERK) in region CA1. In fact, the degree and kinetics of L-LTP suppression in the dnMEK1 mice was equivalent to suppression of L-LTP in wild-type mice by the mRNA translation inhibitor anisomycin. These authors did not observe any decrement in E-LTP induced by two trains of HFS in the dnMEK1 mice, but the decrement of L-LTP (induced by four trains of HFS) developed within minutes in both dnMEK1 and anisomycin-treated mice. This is consistent with our results because E-LTP induced by two trains of HFS in mouse is not sensitive to the MEK inhibitors U0126 or SL327 (Selcher et al., 2003). Therefore, we tested whether E-LTP induced with our acute theta-burst protocol was dependent on protein synthesis using anisomycin. Not only did anisomycin produce a partial suppression of this E-LTP, but also both the magnitude and kinetics of E-LTP blockade with anisomycin (Fig. 5A) were nearly identical to those of U0126 (Fig. 5B) and STO-609 (Fig. 5C), indicating that the CaMKK/ERK pathway in E-LTP may exert its effects primarily through a translation-dependent mechanism. Furthermore, anisomycin treatment did not significantly affect the dendritic field responses (area under the curve) during theta-bursts (data not shown), as was the case with STO-609 and U0126 (Fig. 2C). Our observation that E-LTP generated by theta-burst stimulation are equally sensitive to STO-609 (Fig. $2 D$ ) and anisomycin (Fig. 5A) suggest that protein synthesis during theta-burst E-LTP is regulated by CaMKK and is required for concurrent CaMKK-dependent LTP expression. Indeed, treatment of slices with STO-609 was able to occlude further inhibition of E-LTP by U0126 (Fig. 5D).

Regulation of general mRNA translation by ERK during LTP may be related to phosphorylation of several translation fac-

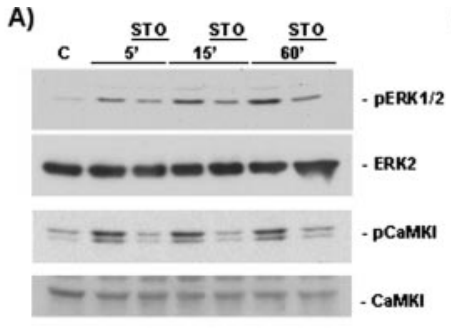

B)

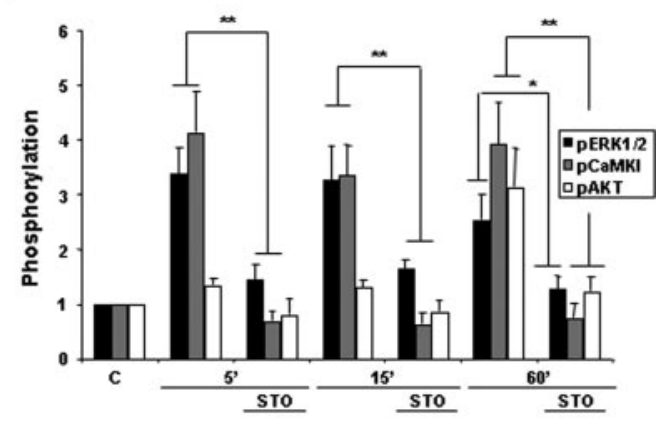

c)

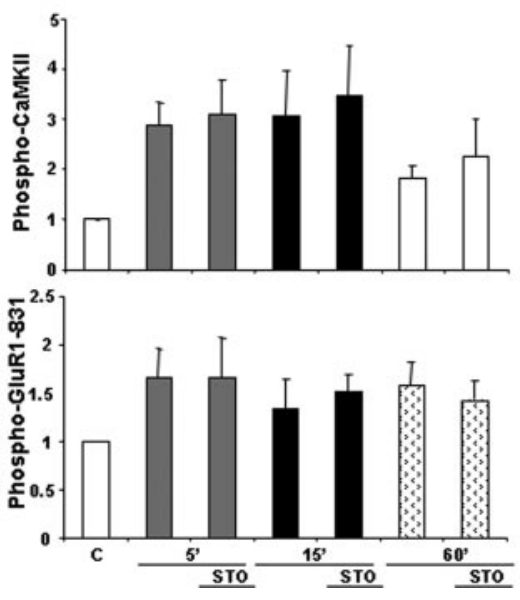

Figure 3. LTP-activation of CaMKI, Ras-GRF1, and ERK requires CaMKK. Mouse hippocampal slices were preincubated without or with ST0-609 (ST0; $5 \mu \mathrm{M}, 30 \mathrm{~min}$ ) and subjected to theta-burst stimulation as in Figure 2D. The activation states, assessed by phospho-specific antibodies (see Fig. 1), of ERK1/2, CaMKI, and AKT ( $A, B)$; Ras-GRF1 ( $C$ ); and CaMKII and the GluR1 subunit of the AMPA-type glutamate receptor (a CaMKII substrate) $(D)$ were determined at the indicated times. Mean $\pm \mathrm{SE} ; n=6 .{ }^{*} p \leq 0.05$; ${ }^{* *} p \leq 0.01$. C, Control.

A)

B)
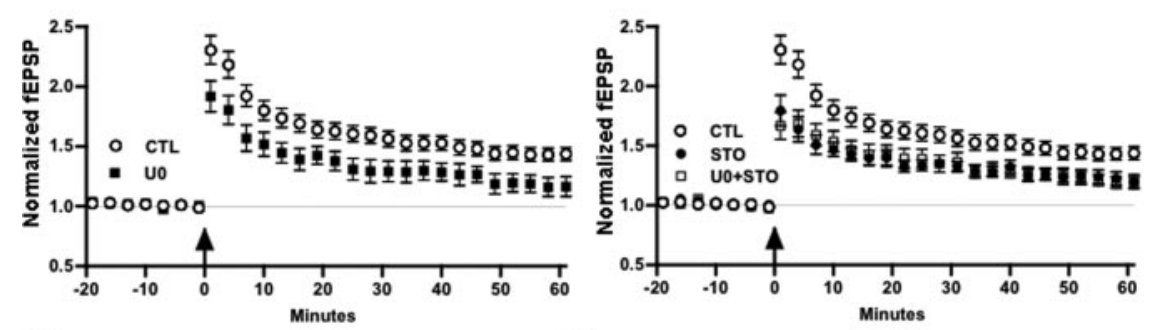

C)

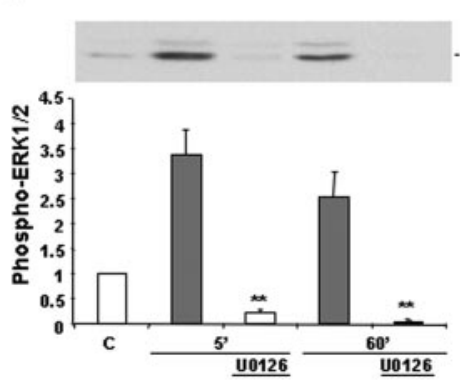

D)

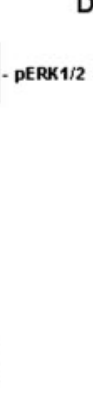

Figure 4. CaMKK and ERK mediate E-LTP via a common mechanism. $A, B$, Mouse hippocampal slices were treated without or with the MEK inhibitor U0126 (U0; $10 \mu \mathrm{M})$ and/or the CaMKK inhibitor ST0-609 (ST0; $5 \mu \mathrm{m}$ ) by bath application as in Figure 2 D for 30 min before and 5 min after E-LTP induction. Control (CTL), $n=24 ; \mathrm{U} 0126, n=10 ; \mathrm{STO}-609, n=11 ; \mathrm{U} 0126$ plus ST0-609, $n=$ 10. $C, D$, At various times after E-LTP induction (as in Fig. 2D), the activation status of ERK ( $C$ ) and CaMKI, AKT, CaMKII, and Ras-GRF1 $(D)$ was determined at the indicated times. Mean $\pm \mathrm{SE} ; n=5 .{ }^{* *} p \leq 0.01$. 
A)

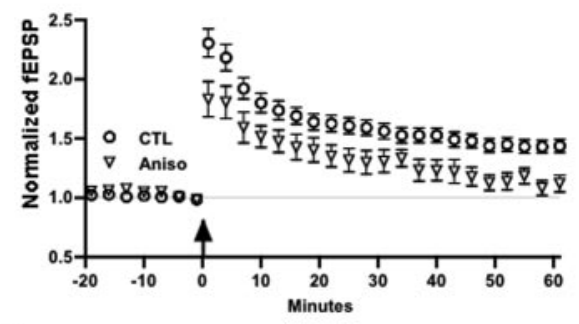

C)

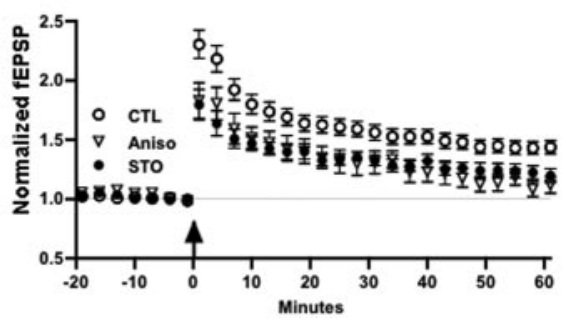

B)

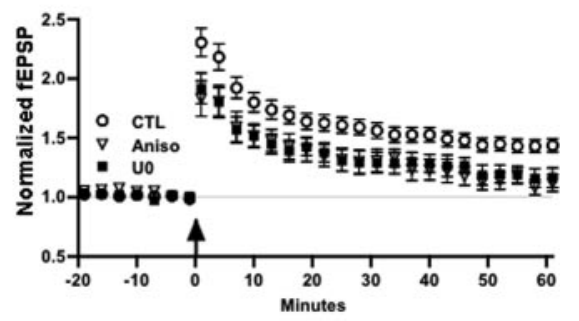

D)

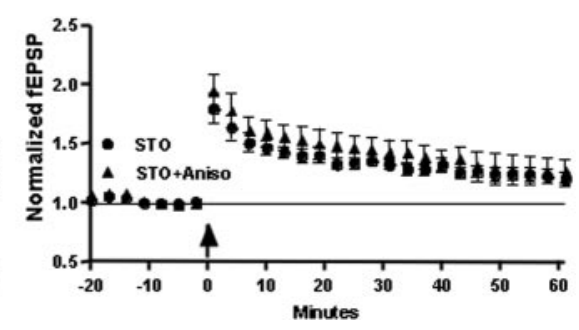

Figure 5. Inhibitors of CaMKK and MEK suppress LTP by a translation-dependent pathway. $A$, Mouse hippocampal slices were treated by bath application with the translation inhibitor anisomycin (Aniso; $40 \mu \mathrm{M}$ ) 30 min before and for the duration of recording after E-LTP (as in Fig. 2D). $n=8$. Note that the magnitude and kinetics of anisomycin suppression of LTP are identical to those of U0126 (UO; B) and ST0-609 (STO; $C$ and are occluded by STO-609 (D). CTL, Control.

A)

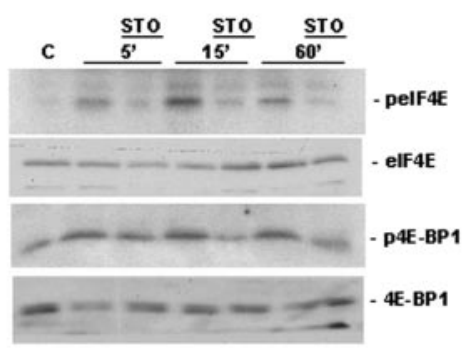

C)

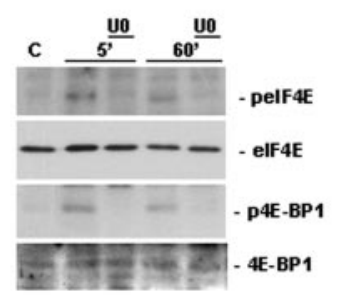

B)

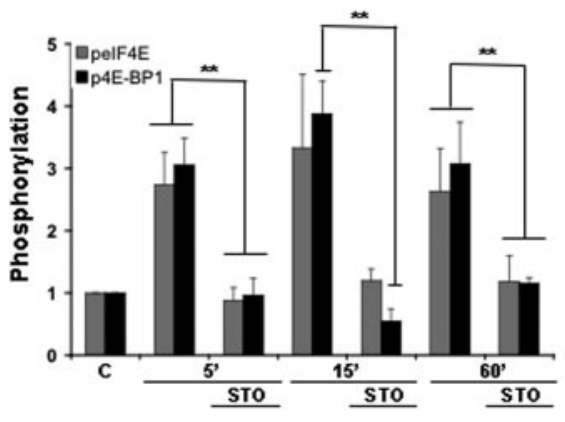

D)

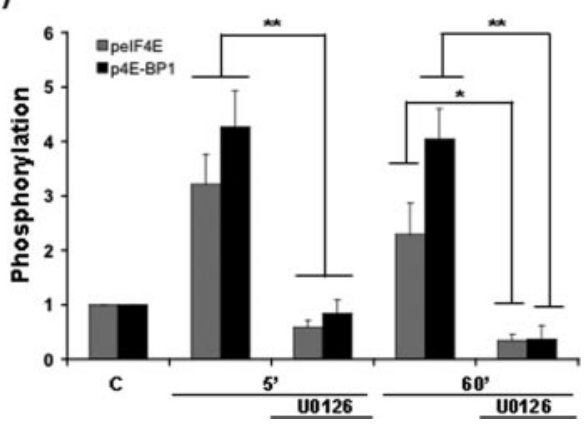

Figure 6. Translation factor activation in E-LTP requires CaMKK and ERK. Mouse hippocampal slices were preincubated with the indicated pharmacological reagents (see Fig. 1) and then subjected to E-LTP induction (as in Fig. 2D). The activation state of translation factors elF4E and its inhibitory binding protein 4E-BP1 were determined using phospho-specific antibodies against their respective activation sites. Mean $\pm \mathrm{SE} ; n=6(B)$ or $n=5(D)$. ST0, STO-609; U0, U0126; C, Control. ${ }^{*} p \leq 0.05 ;{ }^{* *} p \leq 0.01$.

tors, including eIF4E and its inhibitory binding protein $4 \mathrm{E}-\mathrm{BP} 1$ (Kelleher et al., 2004). Induction of LTP with our acute thetaburst protocol produced a rapid ( $5 \mathrm{~min}$ ) and sustained (60 $\mathrm{min}$ ) phosphorylation of eIF4E and 4E-BP1 (Fig. 6A-D), both of which required CaMKK activity because STO-609, when present during LTP induction, was inhibitory at all time points examined. U0126 completely blocked phosphorylation of eIF4E and
4E-BP1 (Fig. 6D), highlighting the importance of eIF4E and 4E-BP1 in translationdependent LTP. We conclude that regulatory eIF4E and 4E-BP1 phosphorylations are mediated by the CaMKK/ERK pathway in NMDA receptor-dependent thetaburst LTP.

\section{Discussion}

$\mathrm{Ca}^{2+}$ signaling and protein phosphorylation play essential roles in regulating the multiple mechanisms that produce hippocampal CA1 LTP, and recent studies have focused on the roles of CaMKII (Soderling et al., 2001; Lisman et al., 2002), CaMKIV (Kang et al., 2001; Kasahara et al., 2001), and ERK (Morozov et al., 2003; Selcher et al., 2003; Kelleher et al., 2004). Although ERK activation during LTP induction is $\mathrm{Ca}^{2+}$ dependent, the mechanisms responsible for this are unclear (Thomas and Huganir, 2004). Using cultured hippocampal neurons and acute slices, we reveal a robust $\mathrm{Ca}^{2+}$-mediated activation of CaMKI by CaMKK that is required for both the activation of ERK and the full expression of NMDAreceptor dependent LTP. Additionally, our study suggests that CaMKK mediates mRNA translation, as measured by regulatory phosphorylation of several translation initiation factors, via ERK during LTP. Together, our data demonstrate that CaMKK and CaMKI are required for ERK activation, regulatory phosphorylation of two limiting general translation factors, and E-LTP at the Schaeffer-collateral CA1 synapse.

\section{A role for CaMKI in E-LTP}

Previous studies have examined the role of the CaMKK cascade in LTP, focusing on the role of CaMKIV in CREB/CBPmediated gene transcription. LTP induction does result in activation of CaMKIV (Kasahara et al., 2001), but, because CaMKIV is predominantly nuclear, it is unlikely to play a major role in cytoplasmic ERK activation. Indeed, nuclearlocalized dominant-negative CaMKIV has no effect on ERK activation in NG108 cells (Schmitt et al., 2004) or cultured hippocampal neurons (Fig. $1 B$ ). Furthermore, $\mathrm{Ca}^{2+}$-dependent ERK activation in dnCaMKIV-expressing (Kang et al., 2001) and CaMKIV knock-out mice (Ho et al., 2000) was normal. Moreover, expression of dnCaMKIV in region CA1 of hippocampus does not inhibit E-LTP induced with theta burst (Kang et al., 2001), nor does knocking out the CaMKIV gene inhibit E-LTP induced by HFS (Ho et al., 2000). These findings support the conclusion that CaMKI, but not CaMKIV or AKT, mediates the CaMKKdependent portion of LTP induction and E-LTP. 
Although LTP induced with theta bursts was sensitive to U0126 or STO-609, it was not completely inhibited during the first hour ( $\sim 50 \%$ inhibition) (Fig. $2 E, F)$. This observation is consistent with the well established role in LTP of CaMKII to phosphorylate the AMPA receptor subunit GluR1, thereby enhancing its conductance (Derkach et al., 1999). This mechanism is thought to mediate $\sim 50 \%$ of the change in synaptic efficacy that occurs during E-LTP (Benke et al., 1998; Poncer et al., 2002). We found that neither the activation of CaMKII nor the phosphorylation of GluR1 at Ser ${ }^{831}$ were affected by STO-609 during LTP, demonstrating both the specificity of STO-609 and that CaMKK and ERK effects were independent of CaMKII actions. We interpret these findings as evidence that the CaMKK/ERK and CaMKII pathways mediate E-LTP by distinct mechanisms. However, STO-609 did completely suppress L-LTP after $\sim 2 \mathrm{~h}$, consistent with a dual role for CaMKK in regulation of CaMKI (E-LTP) and CaMKIV (L-LTP). This is consistent with the report that a mouse lacking the $\beta$ isoform of CaMKK, which is thought to be predominantly nuclear and to regulate CaMKIV, showed no deficit in E-LTP but lacked L-LTP (Peters et al., 2003)

CaMKI has been shown previously to promote hippocampal axon outgrowth and growth cone dynamics (Wayman et al., 2004), structural components of plasticity. In this study, we find that CaMKI is robustly activated by CaMKK after induction of E-LTP with theta bursts. This stimulation of the CaMKK/CaMKI pathway was required for ERK activation, providing a compelling mechanism for $\mathrm{Ca}^{2+}$-mediated ERK activation during LTP. Accordingly, the effects of pharmacological inhibition of CaMKK and ERK (with STO-609 and U0126, respectively) on E-LTP are mutually occlusive, indicating that these kinases share the same pathway. We chose theta burst rather than HFS to induce E-LTP because it has been shown in mice that U0126 does not block E-LTP resulting from HFS (two trains of $100 \mathrm{~Hz}$ ) but is partially inhibited using theta-burst induction (Selcher et al., 2003). However, we should point out that we used lower stimulation intensity, as well as older animals, than used by Selcher et al. to demonstrate a role for ERK in temporal integration during LTP induction. These differences may help explain why inhibition of the ERK pathway did not significantly reduce the integrated field responses during E-LTP induction in our study. It is interesting that induction of LTP by both of our theta-burst protocols was partially suppressed by STO-609 (Fig. $2 F$ ) and induction of L-LTP by HFS (4 trains of $100 \mathrm{~Hz}, 5 \mathrm{~min}$ apart) was partially suppressed by anisomysin (Kelleher et al., 2004), even during the E-LTP phase (first $60 \mathrm{~min}$ ). These results suggest that the CaMKK, ERK, and protein synthesis-dependent processes can affect LTP within minutes depending on the induction protocol.

In addition to CaMKII-mediated phosphorylation of AMPA-Rs to enhance conductivity (Derkach et al., 1999), recruitment of additional AMPA-Rs to synapses is thought to be a second major postsynaptic mechanism of E-LTP expression at the CA1 synapse (Malinow and Malenka, 2002). One possible explanation for the rapid deficit of LTP after STO-609, U0126, or anisomycin treatment could be that synaptic delivery of AMPA receptors may be coupled to translation. Indeed, it has been shown that the Ras/ERK pathway is required for this rapid trafficking of AMPA-Rs (Zhu et al., 2002). AMPA-R trafficking is also dependent on CaMK activity, with current evidence supporting a role for CaMKII (Poncer et al., 2002). However, because recent work indicates that CaMKII probably has either an inhibitory effect on ERK (Oh et al., 2004) or no effect (Krapivinsky et al., 2004), we propose that the requirement for a CaMK in
AMPA-R trafficking may be attributable to CaMKK/CaMKI activation of ERK.

\section{ERK regulation in synaptic plasticity}

A role for ERK1/2 in NMDA receptor-dependent hippocampal LTP is well established (Sweatt, 2004; Thomas and Huganir, 2004), and a number of mechanisms for how $\mathrm{Ca}^{2+}$ may activate ERK have been proposed, including roles for Pyk2 and Src, CalDAG-GEFs (calcium- and diacylglycerol-regulated guanine nucleotide exchange factors), EGF (epidermal growth factor) receptor transactivation, and Ras-GRF1/2. The data presented here demonstrate that NMDA receptor-dependent ERK activation during E-LTP requires CaMKK acting through CaMKI. Other components of NMDA receptor-dependent ERK activation include Ras (Thomas and Huganir, 2004) and its activator RasGRF1 that directly interacts with the NMDA-receptor and is required for ERK activation (Krapivinsky et al., 2003; Tian et al., 2004). Ras-GRF is regulated through phosphorylation of Ser ${ }^{916}$ by several kinases, including PKA and CaMKII, and this phosphorylation is required for full activation of Ras and for neurite outgrowth (Mattingly, 1999; Baouz et al., 2001; Yang et al., 2003). We find that Ser ${ }^{916}$ is rapidly phosphorylated in response to NMDA treatment and theta-burst stimulation in a CaMKKdependent manner. It should be noted that Ras-GRF1 contains multiple phosphorylation sites (Baouz et al., 2001), and activation appears complex and may be regulated by the binding of cofactor(s) such as CaM and/or by its subcellular localization (Buchsbaum et al., 1996; Arozarena et al., 2004). In this context, Ras-GRF1 is a very poor in vitro substrate for activated CaMKI relative to PKA (T. Saneyoshi, unpublished observation). The precise mechanism for CaMKK-mediated activation of the Ras pathway remains an area of investigative interest.

\section{Regulation of translational activation by CaMKK and ERK}

ERK activation has been implicated in regulating multiple aspects of LTP, including gene transcription (Thomas and Huganir, 2004), AMPA-R trafficking (Zhu et al., 2002), dendritic excitability (Morozov et al., 2003), and translation factor phosphorylation (Kelleher et al., 2004). The data presented here are consistent with a role of ERK in regulation of mRNA translation via phosphorylation of both eIF4E and 4E-BP1 (Fig. 6). Phosphorylation of 4E-BP1 frees up additional eIF4E, a limiting translation factor, and phosphorylation of eIF4E enhances its functionality (Raught et al., 2000). Moreover, the partial inhibition of E-LTP by the protein synthesis inhibitor anisomycin was identical to inhibition by U0126 and STO-609 and occluded by STO-609, implying that CaMKK and ERK regulate E-LTP by a translation-dependent mechanism.

There are several reports documenting inhibition of NMDA receptor-dependent LTP by anisomycin and other translation inhibitors during the early phase in hippocampus and amygdala (Huang et al., 2000; Kelleher et al., 2004). The partial inhibition of E-LTP by anisomycin in our acute theta-burst protocol was very rapid (Fig. 5), but it should be noted that translation of a typical $50 \mathrm{kDa}$ protein, at a rate of seven amino acids per second, would only require $\sim 1 \mathrm{~min}$. Indeed, a significant increase in dendritic CaMKII, attributable to localized synthesis, was observed within 5 min of LTP induction (Ouyang et al., 1999). Additionally, anisomycin was present for $30 \mathrm{~min}$ before LTP induction, and, although it had little effect on basal synaptic transmission, it could suppress basal synthesis of some component necessary for the rapid insertion or modulation of AMPA-Rs during induction (Malinow and Malenka, 2002). Alternatively, it is possible that 
translation and postsynaptic exocytosis are coupled through the secretory pathway and that inhibiting one process may affect the other. Furthermore, it is now recognized that protein synthesis from mRNAs localized within dendrites and even dendritic spines is essential for synaptic plasticity, so the possibility that protein synthesis may have acute regulatory effects has to be considered. CaMKK, CaMKI (Wayman et al., 2004), ERK (Wu et al., 2001b), and eIF4E (Asaki et al., 2003; Smart et al., 2003) are all localized in dendrites, as is the mRNA for the GluR1 subunit of the AMPA-R (Job and Eberwine, 2001). Thus, it will be important to determine whether the CaMKK/CaMKI pathway regulates a pool of ERK that in turn stimulates AMPA-R synthesis and/or trafficking to synapses.

\section{References}

Agell N, Bachs O, Rocamora N, Villalonga P (2002) Modulation of the Ras/ Raf/MEK/ERK pathway by $\mathrm{Ca}^{2+}$ and calmodulin. Cell Signal 14:649-654.

Arozarena I, Matallanas D, Berciano MT, Sanz-Moreno V, Calvo F, Munoz MT, Egea G, Lafarga M, Crespo P (2004) Activation of H-Ras in the endoplasmic reticulum by the RasGRF family guanine nucleotide exchange factors. Mol Cell Biol 24:1516-1530.

Asaki C, Usuda N, Nakazawa A, Kametani K, Suzuki T (2003) Localization of translational components at the ultramicroscopic level at postsynaptic sites of the rat brain. Brain Res 972:168-176.

Baouz S, Jacquet E, Accorsi K, Hountondji C, Balestrini M, Zippel R, Sturani E, Parmeggiani A (2001) Sites of phosphorylation by protein kinase A in CDC25Mm/GRF1, a guanine nucleotide exchange factor for Ras. J Biol Chem 276:1742-1749.

Barria A, Muller D, Derkach V, Griffith LC, Soderling TR (1997) Regulatory phosphorylation of AMPA-type glutamate receptors by CaM-KII during long-term potentiation. Science 276:2042-2045.

Benke TA, Luthi A, Isaac JT, Collingridge GL (1998) Modulation of AMPA receptor unitary conductance by synaptic activity. Nature 393:793-797.

Buchsbaum R, Telliez JB, Goonesekera S, Feig LA (1996) The N-terminal pleckstrin, coiled-coil, and IQ domains of the exchange factor Ras-GRF act cooperatively to facilitate activation by calcium. Mol Cell Biol 16:4888-4896.

Chang BH, Mukherji S, Soderling TR (1998) Characterization of a calmodulin kinase II inhibitor protein in brain. Proc Natl Acad Sci USA 95:10890-10895.

Colbran RJ, Brown AM (2004) Calcium/calmodulin-dependent protein kinase II and synaptic plasticity. Curr Opin Neurobiol 14:318-327.

Derkach V, Barria A, Soderling TR (1999) $\mathrm{Ca}^{2+} /$ calmodulin-kinase II enhances channel conductance of alpha-amino-3-hydroxy-5-methyl-4isoxazolepropionate type glutamate receptors. Proc Natl Acad Sci USA 96:3269-3274.

Enslen H, Sun P, Brickey D, Soderling SH, Klamo E, Soderling TR (1994) Characterization of $\mathrm{Ca}^{2+} /$ calmodulin-dependent protein kinase IV. Role in transcriptional regulation. J Biol Chem 269:15520-15527.

Fukunaga K, Soderling TR, Miyamoto E (1992) Activation of $\mathrm{Ca}^{2+} /$ calmodulin-dependent protein kinase II and protein kinase $\mathrm{C}$ by glutamate in cultured rat hippocampal neurons. J Biol Chem 267:22527-22533

Ho N, Liauw JA, Blaeser F, Wei F, Hanissian S, Muglia LM, Wozniak DF, Nardi A, Arvin KL, Holtzman DM, Linden DJ, Zhuo M, Muglia LJ, Chatila TA (2000) Impaired synaptic plasticity and cAMP response element-binding protein activation in $\mathrm{Ca}^{2+} /$ calmodulin-dependent protein kinase type IV/Gr-deficient mice. J Neurosci 20:6459-6472.

Huang YY, Martin KC, Kandel ER (2000) Both protein kinase A and mitogen-activated protein kinase are required in the amygdala for the macromolecular synthesis-dependent late phase of long-term potentiation. J Neurosci 20:6317-6325.

Impey S, Fong AL, Wang Y, Obrietan K, Wayman GA, Storm DR, Soderling TR, Goodman RH (2002) Phosphorylation of CBP mediates transcriptional activation by neural activity and CaM kinase IV. Neuron 34:235-244.

Jensen KF, Ohmstede CA, Fisher RS, Sahyoun N (1991) Nuclear and axonal localization of $\mathrm{Ca}^{2+} /$ calmodulin-dependent protein kinase type $\mathrm{Gr}$ in rat cerebellar cortex. Proc Natl Acad Sci USA 88:2850-2853.
Job C, Eberwine J (2001) Localization and translation of mRNA in dendrites and axons. Nat Rev Neurosci 2:889-898.

Kandel ER (2001) The molecular biology of memory storage: a dialogue between genes and synapses. Science 294:1030-1038.

Kang H, Sun LD, Atkins CM, Soderling TR, Wilson MA, Tonegawa S (2001) An important role of neural activity-dependent CaM-KIV signaling in the consolidation of long-term memory. Cell 106:771-783.

Kasahara J, Fukunaga K, Miyamoto E (2001) Activation of calcium/ calmodulin-dependent protein kinase IV in long term potentiation in the rat hippocampal CA1 region. J Biol Chem 276:24044-24050.

Kelleher III RJ, Govindarajan A, Jung HY, Kang H, Tonegawa S (2004) Translational control by MAPK signaling in long-term synaptic plasticity and memory. Cell 116:467-479.

Krapivinsky G, Krapivinsky L, Manasian Y, Ivanov A, Tyzio R, Pellegrino C, Ben-Ari Y, Clapham DE, Medina I (2003) The NMDA receptor is coupled to the ERK pathway by a direct interaction between NR2B and RasGRF1. Neuron 40:775-784.

Krapivinsky G, Medina I, Krapivinsky L, Gapon S, Clapham DE (2004) SynGAP-MUPP1-CaMKII synaptic complexes regulate p38 MAP kinase activity and NMDA receptor-dependent synaptic AMPA receptor potentiation. Neuron 43:563-574

Lemrow SM, Anderson KA, Joseph JD, Ribar TJ, Noeldner PK, Means AR (2004) Catalytic activity is required for calcium/calmodullin-dependent protein kinase IV to enter the nucleus. J Biol Chem 279:11664-11671.

Lisman J, Schulman H, Cline H (2002) The molecular basis of CaMKII function in synaptic and behavioural memory. Nat Rev Neurosci 3:175-190.

Lynch MA (2004) Long-term potentiation and memory. Physiol Rev 84:87-136.

Malenka RC (2003) The long-term potential of LTP. Nat Rev Neurosci 4:923-926.

Malenka RC, Nicoll RA (1999) Long-term potentiation-a decade of progress? Science 285:1870-1874.

Malinow R, Malenka RC (2002) AMPA receptor trafficking and synaptic plasticity. Annu Rev Neurosci 25:103-126.

Mattingly RR (1999) Phosphorylation of serine 916 of Ras-GRF1 contributes to the activation of exchange factor activity by muscarinic receptors. J Biol Chem 274:37379-37384.

Means AR (2000) Regulatory cascades involving calmodulin-dependent protein kinases. Mol Endocrinol 14:4-13.

Morozov A, Muzzio IA, Bourtchouladze R, Van-Strien N, Lapidus K, Yin D, Winder DG, Adams JP, Sweatt JD, Kandel ER (2003) Rap1 couples cAMP signaling to a distinct pool of p42/44MAPK regulating excitability, synaptic plasticity, learning, and memory. Neuron 39:309-325.

Oh JS, Manzerra P, Kennedy MB (2004) Regulation of the neuron-specific Ras GTPase activating protein, synGAP, by $\mathrm{Ca}^{2+} /$ calmodulin-dependent protein kinase II. J Biol Chem 279:17980-17988.

Ouyang Y, Rosenstein A, Kreiman G, Schuman EM, Kennedy MB (1999) Tetanic stimulation leads to increased accumulation of $\mathrm{Ca}^{2+} /$ calmodulin-dependent protein kinase II via dendritic protein synthesis in hippocampal neurons. J Neurosci 19:7823-7833.

Pearson G, Robinson F, Beers Gibson T, Xu BE, Karandikar M, Berman K, Cobb MH (2001) Mitogen-activated protein (MAP) kinase pathways: regulation and physiological functions. Endocr Rev 22:153-183.

Peters M, Mizuno K, Ris L, Angelo M, Godaux E, Giese KP (2003) Loss of $\mathrm{Ca}^{2+} /$ calmodulin kinase kinase $\beta$ affects the formation of some, but not all, types of hippocampus-dependent long-term memory. J Neurosci 23:9752-9760.

Poncer JC, Esteban JA, Malinow R (2002) Multiple mechanisms for the potentiation of AMPA receptor-mediated transmission by $\alpha-\mathrm{Ca}^{2+}$ / calmodulin-dependent protein kinase II. J Neurosci 22:4406-4411.

Raught B, Gingras AC, Sonenberg N (2000) Regulation of ribosomal recruitment in eukaryotes. Cold Spring Harbor, NY: Cold Spring Harbor Press.

Schmitt JM, Wayman GA, Nozaki N, Soderling TR (2004) Calcium activation of ERK mediated by calmodulin kinase I. J Biol Chem 279:24064-24072.

Selcher JC, Weeber EJ, Christian J, Nekrasova T, Landreth GE, Sweatt JD (2003) A role for ERK MAP kinase in physiologic temporal integration in hippocampal area CA1. Learn Mem 10:26-39.

Smart FM, Edelman GM, Vanderklish PW (2003) BDNF induces translocation of initiation factor $4 \mathrm{E}$ to $\mathrm{mRNA}$ granules: evidence for a role of 
synaptic microfilaments and integrins. Proc Natl Acad Sci USA 100:14403-14408.

Soderling TR (1999) The $\mathrm{Ca}^{2+}$-calmodulin-dependent protein kinase cascade. Trends Biochem 24:232-235.

Soderling TR (2000) CaM-kinases: modulators of synaptic plasticity. Curr Opin Neurobiol 10:375-380.

Soderling TR, Derkach VA (2000) Postsynaptic protein phosphorylation and LTP. Trends Neurosci 23:75-80.

Soderling TR, Chang B, Brickey D (2001) Cellular signaling through multifunctional $\mathrm{Ca}^{2+} /$ calmodulin-dependent protein kinase II. J Biol Chem 276:3719-3722.

Song I, Huganir RL (2002) Regulation of AMPA receptors during synaptic plasticity. Trends Neurosci 25:578-588.

Suizu F, Fukuta Y, Ueda K, Iwasaki T, Tokumitsu H, Hosoya H (2002) Characterization of $\mathrm{Ca}^{2+} /$ calmodulin-dependent protein kinase I as a myosin II regulatory light chain kinase in vitro and in vivo. Biochem J 367:335-345.

Sweatt JD (2004) Mitogen-activated protein kinases in synaptic plasticity and memory. Curr Opin Neurobiol 14:311-317.

Thomas GM, Huganir RL (2004) MAPK cascade signalling and synaptic plasticity. Nat Rev Neurosci 5:173-183.

Tian X, Gotoh T, Tsuji K, Lo EH, Huang S, Feig LA (2004) Developmentally regulated role for Ras-GRFs in coupling NMDA glutamate receptors to Ras, Erk and CREB. EMBO J 23:1567-1575.

Tokumitsu H, Inuzuka H, Ishikawa Y, Ikeda M, Saji I, Kobayashi R (2002)
STO-609, a specific inhibitor of the $\mathrm{Ca}^{2+} /$ calmodulin-dependent protein kinase kinase. J Biol Chem 277:15813-15818.

Treisman R (1996) Regulation of transcription by MAP kinase cascades. Curr Opin Cell Biol 8:205-215.

Wayman GA, Kaech S, Grant WF, Davare M, Impey S, Tokumitsu H, Nozaki N, Banker G, Soderling TR (2004) Regulation of axonal extension and growth cone motility by calmodulin-dependent protein kinase I. J Neurosci 24:3786-3794.

Wu GY, Deisseroth K, Tsien RW (2001a) Activity-dependent CREB phosphorylation: convergence of a fast, sensitive calmodulin kinase pathway and a slow, less sensitive mitogen-activated protein kinase pathway. Proc Natl Acad Sci USA 98:2808-2813.

Wu GY, Deisseroth K, Tsien RW (2001b) Spaced stimuli stabilize MAPK pathway activation and its effects on dendritic morphology. Nat Neurosci 4:151-158.

Yang H, Cooley D, Legakis JE, Ge Q, Andrade R, Mattingly RR (2003) Phosphorylation of the Ras-GRF1 exchange factor at Ser916/898 reveals activation of Ras signaling in the cerebral cortex. J Biol Chem 278:13278-13285.

Yano S, Tokumitsu H, Soderling TR (1998) Calcium promotes cell survival through CaM-K kinase activation of the protein-kinase-B pathway. Nature 396:584-587.

Zhu JJ, Qin Y, Zhao M, Van Aelst L, Malinow R (2002) Ras and Rap control AMPA receptor trafficking during synaptic plasticity. Cell 110:443-455. 